Supporting Information

\title{
Evidence for Compression of Escherichia coli K12 \\ Cells under the Effect of $\mathrm{TiO}_{2}$ Nanoparticles
}

Lyudmila V. Zhukova*

Bach Institute of Biochemistry, Research Center of Biotechnology of the Russian Academy of

Sciences. 33, bld. 2 Leninsky Ave., Moscow 119071, Russia

E-mail: 1yudmila zh@inbi.ras.ru 


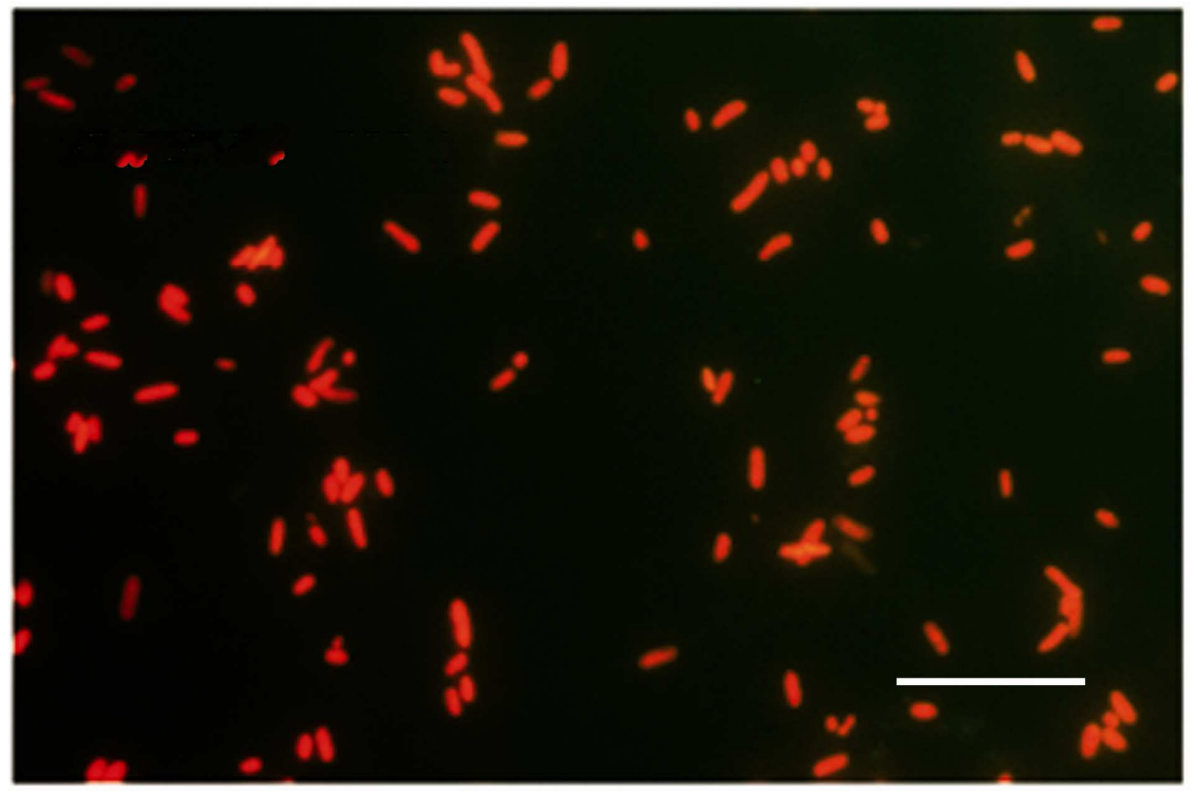

Figure S1. E. coli $\mathrm{K} 12$ cells stained with acridine orange without the addition of $\mathrm{TiO}_{2}$ nanoparticles (scale bar $10 \mu \mathrm{m}$ ). All cells emit red fluorescence (that marks them as active cells). 


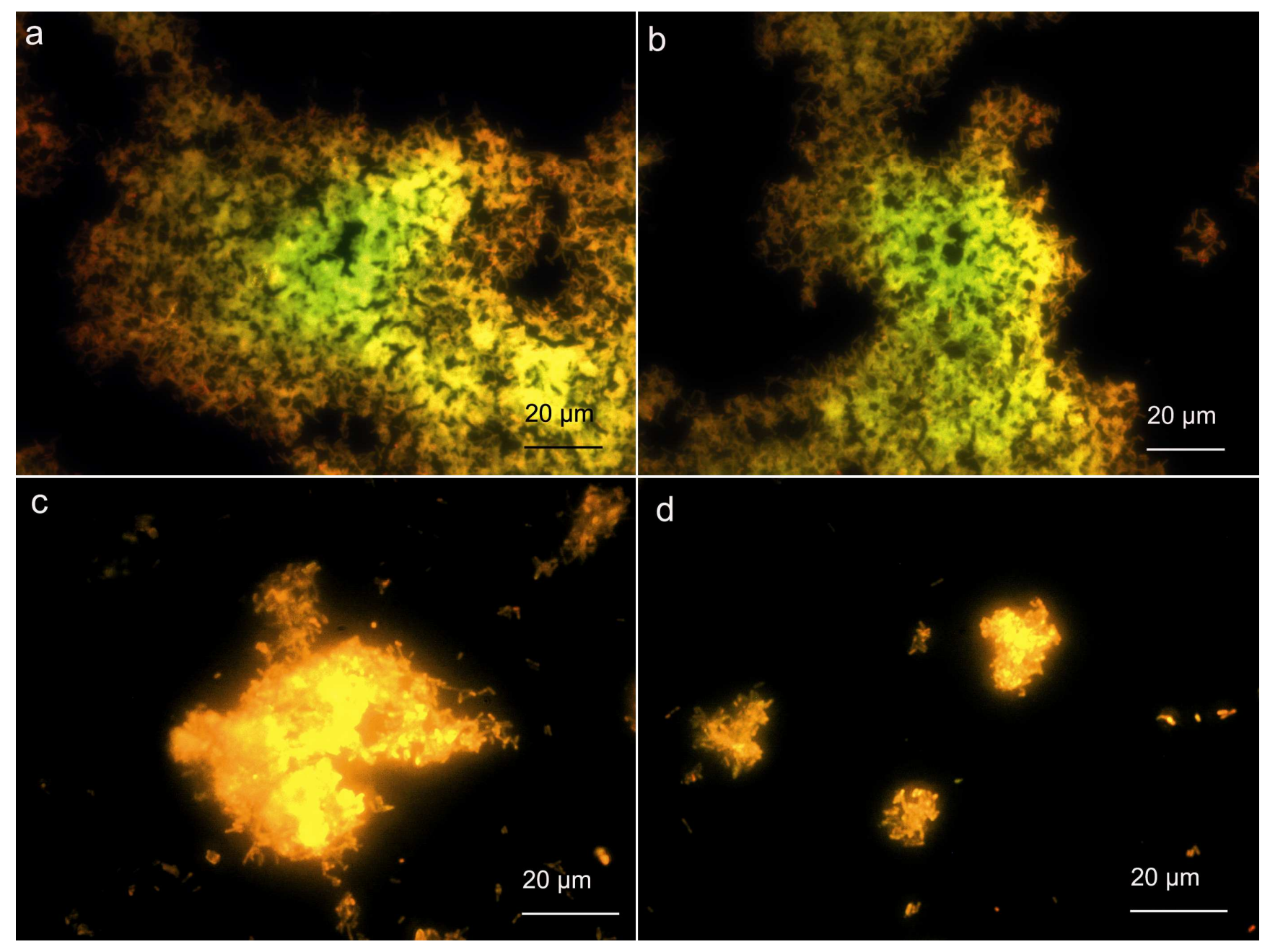

Figure S2. Fluorescence microscopy images of $E$. coli K12 cells stained with acridine orange after exposure to $\mathrm{TiO}_{2}$ nanoparticles for different periods of time under UV-A irradiation. (a, b) Images after 60-min exposure show "cracking" of the aggregates due to local cell compaction. A green cells (inactive) and clusters of cells with yellow-green and bright yellow fluorescence are seen within the aggregates, while cells at their periphery and single cells emit red fluorescence (active). Since the additive mixture of green fluorescence of acridine orange monomers and red fluorescence of acridine orange dimers may result in different shades of yellow color (from greenish to bright yellow), depending on the ratio between these forms, the yellow-green and bright yellow fluorescence within the aggregates could be explained by the enhancement of cell attraction and compression forces and consequent increase in the concentration of red-fluorescing acridine orange dimers at the expense of 
monomers. (c, d) Images after 120-min exposure show that cells in the inner parts of large aggregates are fused into a mass with indistinguishable cell outlines that fluoresces yellow. Some cells on the surface of large aggregates, within small aggregates and single cells still remain active (red fluorescence). Thus, the "greening" (inactivation) of cells begins from the center of the aggregates, and their outer cells are the last to change color. 